\title{
Process Monitoring Systems for Machining Using Audible Sound Energy Sensors
}

\author{
Eva M. Rubio and Roberto Teti \\ National Distance University of Spain (UNED) \\ Spain \\ University of Naples Federico II \\ Italy
}

\section{Introduction}

In the last fifty years, many manufacturers have chosen the implementation of Flexible Manufacturing Systems (FMS) or Computer Integrated Manufacturing (CIM) in their shop floor or, at least, the automation of some of the operations carried out therein with the intention of increasing their productivity and becoming more competitive (Shawaky, 1998; Sokolowski, 2001; Cho, 1999; Govekar, 2000; Brophy, 2002).

With reference to machining operations, the implementation of these systems requires the supervision of different aspects related to the machine (diagnostic and performance monitoring), the tool or tooling (state of wear, lubrication, alignment), the workpiece (geometry and dimensions, surface features and roughness, tolerances, metallurgical damage), the cutting parameters (cutting speed, feed rate, depth of cut), or the process itself (chip formation, temperature, energy consumption) (Byrne, 1995; D'Errico, 1997; Tönshoff, 1988; Grabec, 1998; Inasaki, 1998; Kopac, 2001; Fu, 1996; Masory, 1991; Huang, 1998; Teti, 1995; Teti, 1999).

For the monitoring and control of the above mentioned aspects, it has been necessary to make notable efforts in the development of appropriate process monitoring systems (Burke \& Rangwala, 1991; Chen et al., 1994; Chen et al., 1999; Chen, 2000). Such systems are typically based on different types of sensors such as cutting force and torque, motor current and effective power, vibrations, acoustic emission or audible sound (Desforges, 2004; Peng, 2004; Lin, 2002; Sokolowski, 2001; Ouafi et al., 2000; Karlsson et al., 2000; Chen \& Chen, 1999; Jemielniak et al., 1998; Byrne, 1995; Dornfeld, 1992; Masory, 1991). However, despite all the efforts, standard solutions for their industrial application have not been found yet. The large number and high complexity of the phenomena that take place during machining processes and the possibility to choose among numerous alternatives in each implementation step of the process monitoring system (e.g. cutting test definition, type and location of sensors, monitoring test definition, signal processing method or process modeler selection) are the main responsible for the existence of more than one solution.

The review and analysis of the relevant literature on this topic revealed that it is necessary to develop and implement an experimental system allowing for the systematical 
characterizarion of the different parameters that influence the process before realizing a process monitoring system applicable to industry (Hou, 2003; Jin \& Shi, 2001; Hong, 1993; Malakooti et al., 1995; Venkastesh et al., 1997; Xiaoli et al., 1997; Xu \& Ge, 2004). This will allow to establish an adequate knowledge and control of the critical factors involved in the process monitoring system by means of single factor variations. Moreover, it will be also possible to identify the variations produced by potential spurious sources when the process monitoring system is applied to real situations in the shop floor.

This work reports on the approach for the development of a machining process monitoring system based on audible sound sensors. Audible sound energy appears as one of the most practical techniques since it can serve to replace the traditional ability of the operator, based on his experience and senses (mainly vision and hearing), to determine the process state and react adequately to any machine performance decay $(\mathrm{Lu}, 2000)$. This technique has been attempted for decision making on machining process conditions but it has not been extensively studied yet for applications in industrial process monitoring (Teti, 2004; Teti \& Baciu, 2004). The main critical issues related to the employment of this technology in industry are the need to protect the sensor from the hazardous machining environment (cutting fluids and metal chips) and the environment noise (from adjacent machines, motors, conveyors or other processes) that may contaminate the relevant signals during machining (Lu, 2000; Teti \& Baciu, 2004; Teti et al., 2004; Wilcos, 1997; Clark, 2003).

The principal benefits of audible sound sensors for machining process monitoring are associated with the nature of the sensors employed in the acquisition of the signals. These are, in general, easy to mount on the machine tool, in particular near the machining point, with little or no interference with the machine, the tool, the workpiece or the chip formation. Besides, these sensors, basically microphones, are easy to use in combination with standard phonometers or spectrum analysers. These characteristics of audible sound sensors make the realization of the monitoring procedure quite straightforward. In addition, their maintenance is simple since they only require a careful handling to avoid being hit or damaged. Accordingly, they usually provide for a favourable cost/benefit ratio.

The key novelties of the approach proposed in this work are, on the one hand, the application of a systematic methodology to set up the cutting trials allowing for a better comparison with other similar experimental works and, as a result, the advance in the standardization for the development of such systems. On the other hand, the independent signal analysis of the noise generated by the machine used for the cutting trials and by the working environment allows to filter this noise out of the signals obtained during the actual material processing. Lastly, the possibility has been verified to apply the results of this approach for the development of process monitoring procedures based on sensors of a different type, in particular acoustic emission sensors, where the stress waves produced within the work material do not travel through air but only in the work material itself. The combined application of audible sound energy sensors and acoustic emission sensors could allow for the acquisition of more exhaustive information from both low frequency (audible sound) and high frequency (acoustic emission) acoustic signal analysis. This would decidedly contribute to the realization of the concept of sensor fusion technology for process monitoring (Emel, 1991; Niu et al., 1998).

The described methodology was applied to characterize the audible sound signals emitted by different cutting conditions during milling processes. The classification of audible sound signal features for process monitoring in milling was carried out by graphical analysis and 
parallel distributed data processing based on artificial neural networks. In the following sections, the methodology, the experimentation, the sensor signal detection and analysis methods, and the obtained results are reported and critically assessed.

\section{Methodology}

The methodology proposed for the design and implementation of a process monitoring system based on audible sound energy sensors includes the steps described below.

Cutting tests definition. All the elements involved in the cutting tests, along with their basic characteristics and properties, should be defined in this step, as reported in the systematic methodology proposed in (Rubio \& Teti, 2005) for the establishment of tool condition monitoring systems. In particular, the cutting operation, the machine tool, the workpiece (material and size), the tools (type, material, coating, dimensions and fresh/worn state), the cutting parameters (cutting speed, feed rate, depth of cut) and the possible use of cutting fluid, should be defined. Although this seems obvious and there are in the literature works that report thorough descriptions of the cutting tests (Teti \& Buonadonna, 1999), most of the authors do not provide, or not with the desired detail, all the necessary information to allow for a correct analysis of the results and an adequate comparison with the results obtained by other authors.

Process monitoring tests definition. The monitoring tests dealt with in this work are based on the use of audible sound energy sensors. The broadband sound pressure level of the audible signals is detected by means of sensing devices dedicated to the measure and display this type of signals. All detected audible sound signals are transferred on PC and off-line analysed. In order to verify the repeatability of the monitoring tests, the audible sound signal specimens should be recorded several times $(\geq 3)$ for each cutting condition. The noise of the machine tool running unloaded should be recorded as well in order to be able, later, to characterise the audible sound signals from the cutting process deprived of the disturbing noise generated by both machine and working environment.

Selection of signal processing and decision making methods. To select the most adequate signal processing and decision making methods, a review of the main advanced signal processing (Rubio et al., 2006a) and decision making procedures (Rubio et al., 2006b) used in machining process monitoring based on acoustic sensors was carried out. As a result, the Fast Fourier Transform (FFT) was selected for signal processing and feature extraction whereas supervised Neural Network (NN) paradigms were adopted for signal feature pattern recognition and process conditions decision making.

Experimental layout. The most essential aspects of the experimental layout concern the audible sound sensor location and protection: firstly, the selection of the distance between sensor and cutting point in order to detect the signals correctly, and, secondly, the way to protect the sensor from the chips, the cutting fluid and other pollutants during machining. Besides these actions, particular attention must be paid to isolate the experiments from environmental noise that could seriously contaminate the signal detection.

Performance of the cutting and process monitoring tests. Once all the previous steps have been completed, the machining tests with process monitoring must be carried out. As stated earlier, the tests should be rehearsed several times in order to verify their repeatability. Furthermore, the noise of the machine tool running unloaded should be recorded for its later subtraction from audible sound signals detected during the material removal process. 
Signal processing and decision making. After the sensor monitoring tests, the processing and analysis of the recorded signals by means of the methods selected earlier must be carried out together with the decision making procedure applied to significant signal features: in this work, the FFT for signal processing and supervised NN paradigms for decision making.

Design and implementation of the process monitoring system. On the basis of the issues of the previous steps, the implementation procedure for an on-line machining process monitoring system based on audible sound energy sensors can be proposed.

\section{Application}

According to the methodology described in the previous section, experimental applications were carried out as outlined below.

Cutting tests definition. Following the methodology for the definition of the cutting tests (Rubio \& Teti, 2005), the machining operation was defined as a milling process carried out on a conventional DORMAC FU-100 milling machine. The workpiece was a plate of size of $100 \times 200 \times 40 \mathrm{~mm}$ made of T4-6056 Al alloy. The tool was a fresh 5-teeth milling cutter of $12.16 \times 8.18 \times 5.16 \mathrm{~mm}$, made of WC-Co inserts coated with TiN. The cutting conditions were: spindle speed, $S=800$ and $1000 \mathrm{rpm}$; feed rate, $f=40,80$ and $160 \mathrm{~mm} / \mathrm{min}$ and depth of cut, $d=0.5$ and $1 \mathrm{~mm}$. The tests were conducted under dry cutting conditions. Table 1 summarizes the cutting test description.

\begin{tabular}{|l|l|}
\hline Element & Type/ Characteristics/Properties \\
\hline Cutting operation & Milling \\
\hline Machine Tool & Conventional: DORMAC FU-100 milling machine \\
\hline Workpiece & $\begin{array}{l}\text { Material: } 6056 \text { aluminium alloy with T4 thermal treatment } \\
\text { Dimensions: } 100 \times 200 \times 40 \mathrm{~mm}\end{array}$ \\
\hline Tool & $\begin{array}{l}\text { Type: 5-teeth milling cutter } \\
\text { Material: tungsten particles and cobalt matrix carbide (WC-Co) } \\
\text { Coat material: titanium nitride (TiN) } \\
\text { Dimensions: } 12,16 \times 8,18 \times 5,16 \mathrm{~mm} \\
\text { State: Fresh }\end{array}$ \\
\hline Cutting conditions & $\begin{array}{l}\text { Cutting speed, } S=800-1000 \mathrm{rpm} \\
\text { Feed rate, } f=40-80-160 \mathrm{~mm} / \mathrm{min} \\
\text { Depth of cut, } d=0.5-1 \mathrm{~mm}\end{array}$ \\
\hline Coolant & No \\
\hline
\end{tabular}

Table 1. Summary of the cutting test description.

Process monitoring tests definition. The audible sound energy monitoring system was composed of a Larson Davis 2800 Spectrum Analyser, a standard Larson Davis preamplifier model PRM 900B, a $1 \frac{1}{2}$ " free field high sensitivity sensor and a $1 / 2$ " pre-polarized microphone $(\mathrm{Fu}, 1996)$. All audible sound signals detected by the Larson Davis 2800 Spectrum Analyser were transferred on PC for off-line analysis. 
Selection of signal processing and decision making methods. The selected signal processing and feature extraction method was the FFT and the signal features pattern recognition for decision making was based on supervised NN data processing since this approach had been used in previous works with satisfactory results (Teti, 2004; Teti \& Baciu, 2004).

Experimental layout. Figure 1 shows the experimental layout. The distance between the microphone and the cutting point was set in such a way that, during each machining operation, was approximately equal to $85 \mathrm{~mm}$. Particular attention was paid to protect the microphone from the chips by means of a plastic mesh and to isolate the experimental area from environment noise that could contaminate the detected signals.

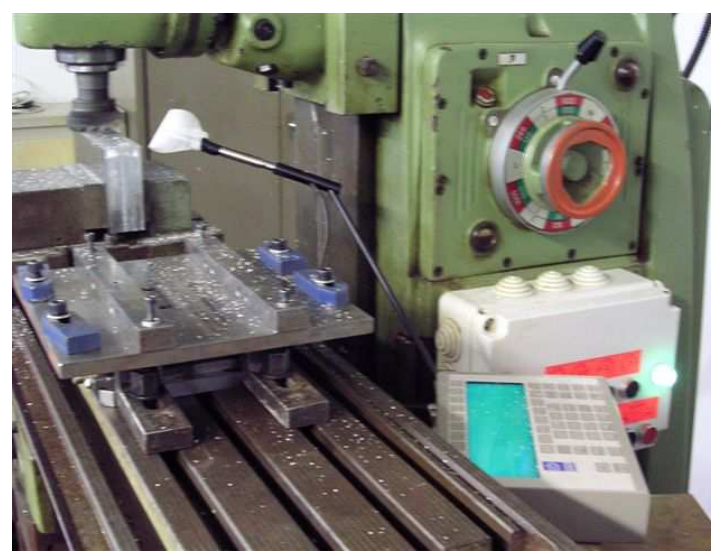

Fig. 1. Experimental layout.

Performance of the cutting and process monitoring tests. The experimental tests carried out with the different cutting conditions are reported in Table 2. Each test was rehearsed 3 times in order to check for repeatability. Simultaneously, the sensor monitoring procedure was applied during each test.

Signal processing and decision making. The spectrum analyser was set to 800 lines acquisition mode and a FFT zoom was set equal to 2 . In this way, as the capture interval was from 0 to $10000 \mathrm{~Hz}$, by dividing this frequency interval into 800 lines, a step of $12.5 \mathrm{~Hz}$ was achieved. Besides the audible sound signal detected in sound Level Meter mode, a series of signal parameters (SUM (LIN) SUM (A), SLOW, SLOW MIN, SLOW MAX, FAST, FAST MIN, FAST MAX, IMPULSE, LEQ, SEL, PEAK, Tmax3 and Tmax5) were obtained and recorded as well. The option "by time" allowed to save the measurements automatically, with end time equal to 10 seconds and step equal to 1 second. The transfer velocity was set at 9600 Baud, which was the same as the velocity imposed to the PC for file transfer. For graphical data processing and display, Spectrum Pressure Level-Noise (Spectrum Pressure Lave, 1998) and Vibrations Works (OS Windows) (Noise and Vibrations Works, 1998) and CA Cricket Graph III (OS Mac) (CA-Cricket Graph III,1992) software packages were used. For NN data processing, the Neural Network Explorer software package was used (Masters, 1993). 


\begin{tabular}{|c|c|c|c|}
\hline Test Id. & $S(r p m)$ & $f(\mathrm{~mm} / \mathrm{min})$ & $d(\mathrm{~mm})$ \\
\hline 1 & 800 & --- & --- \\
\hline 2 & 800 & --- & --- \\
\hline 3 & 800 & --- & --- \\
\hline 4 & 1000 & --- & --- \\
\hline 5 & 1000 & --- & --- \\
\hline 6 & 100 & --- & --- \\
\hline 7 & 800 & 40 & 0.5 \\
\hline 8 & 800 & 40 & 0.5 \\
\hline 9 & 800 & 40 & 0.5 \\
\hline 10 & 800 & 80 & 0.5 \\
\hline 11 & 800 & 80 & 0.5 \\
\hline 12 & 800 & 80 & 0.5 \\
\hline 13 & 800 & 160 & 0.5 \\
\hline 14 & 800 & 160 & 0.5 \\
\hline 15 & 800 & 160 & 0.5 \\
\hline 16 & 800 & 40 & 1 \\
\hline 17 & 800 & 40 & 1 \\
\hline 18 & 800 & 40 & 1 \\
\hline 19 & 800 & 80 & 1 \\
\hline 20 & 800 & 80 & 1 \\
\hline 21 & 800 & 80 & 1 \\
\hline 22 & 800 & 160 & 1 \\
\hline 23 & 800 & 160 & 1 \\
\hline 24 & 800 & 160 & 1 \\
\hline 25 & 1000 & 40 & 0.5 \\
\hline 26 & 1000 & 40 & 0.5 \\
\hline 27 & 1000 & 40 & 0.5 \\
\hline 28 & 1000 & 80 & 0.5 \\
\hline 29 & 1000 & 80 & 0.5 \\
\hline 30 & 1000 & 80 & 0.5 \\
\hline 31 & 1000 & 160 & 0.5 \\
\hline 32 & 1000 & 160 & 0.5 \\
\hline 33 & 1000 & 160 & 0.5 \\
\hline 34 & 1000 & 40 & 1 \\
\hline 35 & 1000 & 40 & 1 \\
\hline 36 & 1000 & 40 & 1 \\
\hline 37 & 1000 & 80 & 1 \\
\hline 38 & 1000 & 80 & 1 \\
\hline 39 & 1000 & 80 & 1 \\
\hline 40 & 1000 & 160 & 1 \\
\hline 41 & 1000 & 160 & 1 \\
\hline 42 & 1000 & 160 & 1 \\
\hline
\end{tabular}

Table 2. Cutting test parameters.

Design and establishment of the process monitoring system. Once the audible sound signals have been fully characterized for each of the diverse cutting conditions, it becomes possible to compare these reference signals with the new ones detected during the normal process operation in such a way that the differences between reference signals and current signals 
allow for the reliable sensor monitoring and control of the machining process. The target is to achieve an on-line monitoring system using as reference the signals conditioned through machine tool and working environment noise filtering and suppression.

\section{Results}

After audible sound signals detection, the repeatability of the tests was verified by calculating the differences between recorded signals and dividing the result by 800 (number of acquisition lines of the spectrum analyser). All the computed values were less than $5 \%$. Then, a reference signal for the machine and environment noise was established as the average of the 3 signals obtained from each of the unloaded machine tool running tests. Figure 2 shows the reference signal in terms of amplitude, $S a(\mathrm{~dB})$, versus frequency, $f(\mathrm{~Hz})$, for the 5 th second of the cutting test with $S=800 \mathrm{rpm}$ and $f=80 \mathrm{~mm} / \mathrm{min}$. Along with the reference signal for the machine and environment noise, the average signals for $d=0.5 \mathrm{~mm}$ and $d=1 \mathrm{~mm}$ under the same $S$ and $f$ conditions were plotted as well.

The reference signal was subtracted from the audible sound signals detected during the actual machining tests to obtain a "difference signal" for classification analysis. All further analyses were carried out using these difference signals (Figure 3).

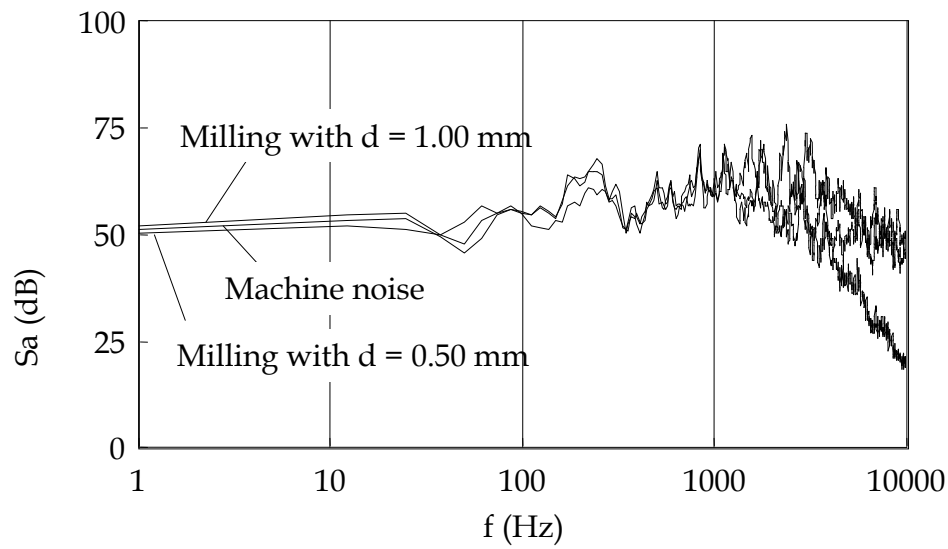

Signal amplitude Sa $(\mathrm{dB})$ vs. frequency $\mathrm{f}(\mathrm{Hz}) 5$ th second

Fig. 2. Signal amplitude $S a(\mathrm{~dB})$ vs. frequency $f(\mathrm{~Hz})$ of the audible sound signals for the 5 th second of each test. Namely, milling with $S=800 \mathrm{rpm}, f=80 \mathrm{~mm} / \mathrm{min}, d=0.5 \mathrm{~mm}$; milling with $S=800 \mathrm{rpm}, f=80 \mathrm{~mm} / \mathrm{min}, d=1 \mathrm{~mm}$, and machine tool running unloaded at $S=800$ rpm. 


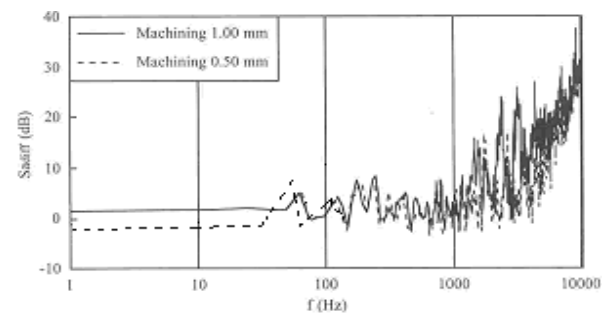

a)

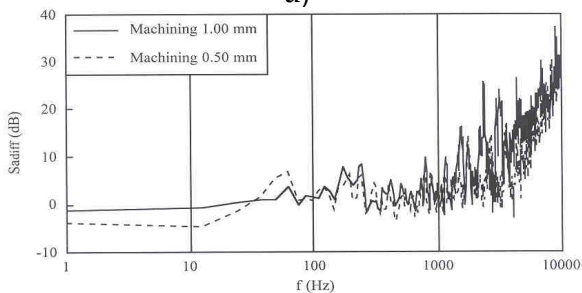

c)

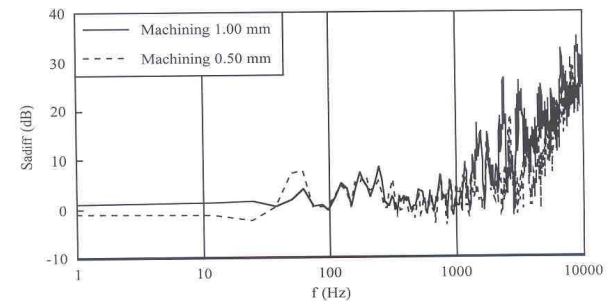

e)

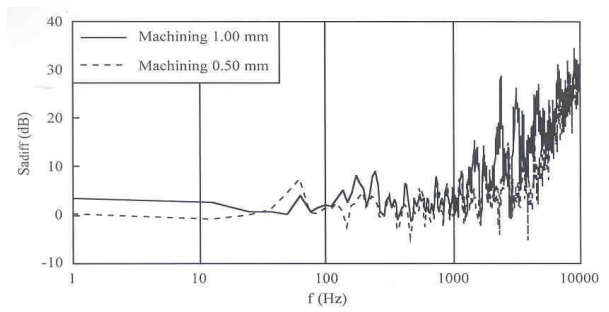

g)

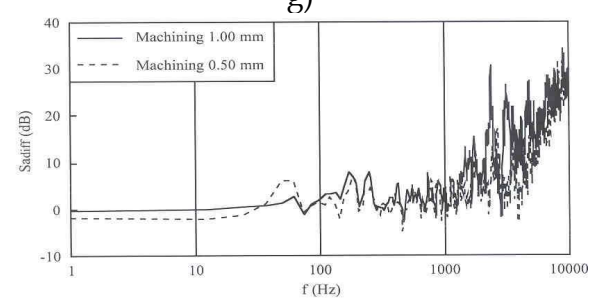

i)

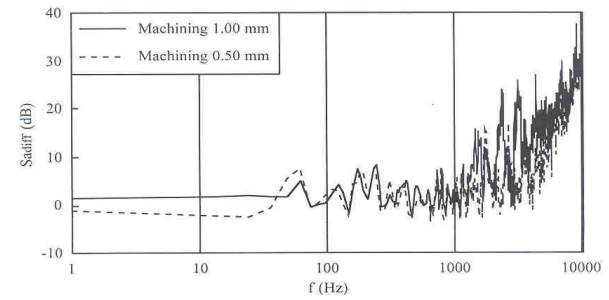

b)

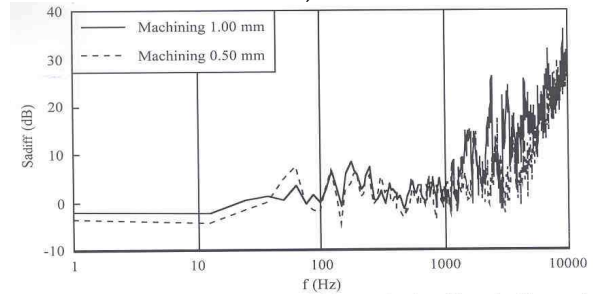

d)

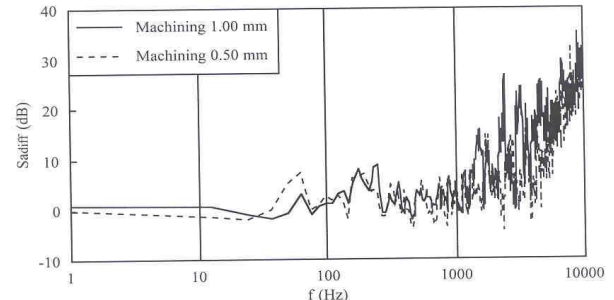

f)

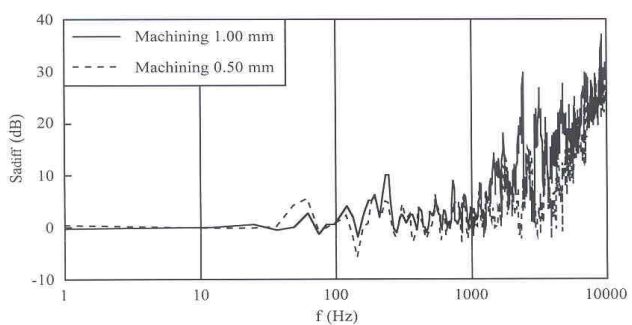

h)

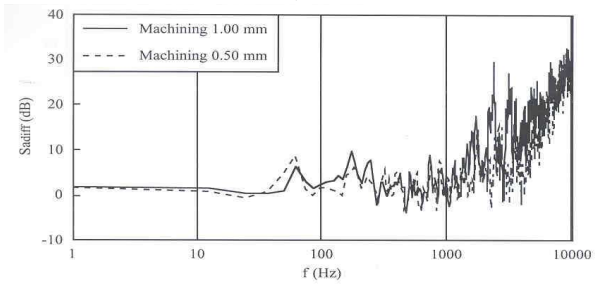

j)

Fig. 3. Amplitude of the difference between machining audible sound and machine tool noise ("difference signal") for each of the ten seconds of cutting test: a) first; b) second; c) thrird; d) fourth; e) fifth; f) sixth; g) seventh; h) eighth; i) ninth; j) tenth second. 
The maximum amplitude of the "difference signal" was evaluated for each frequency interval and for each second of cutting test. The six frequency intervals selected for audible sound signal processing were: 0-0.25, 0.25-0.5, 0.5-1, 1-2.5, 2.5-5, 5-10 kHz. Figure 4 reports examples of the "difference signal" maximum amplitude $S a$ diff $f_{M A X}(\mathrm{~dB})$ versus frequency intervals $\Delta f(\mathrm{~Hz})$ for cutting tests with $S=800 \mathrm{rpm}, f=80 \mathrm{~mm} / \mathrm{min}$ and $d=0.5 \mathrm{~mm}$ or $1 \mathrm{~mm}$ cases, for each of the ten seconds of each cutting test. The figure shows that for frequency values higher than $1 \mathrm{kHz}$ it is possible to discriminate audible sound signals obtained from machining with different depth of cut values.

Graphical representation of data in high dimensions (> 3) feature spaces is not feasible. Thus, the results are presented in a 2 dimensions feature space by pair-wise plotting of frequency intervals maximum signal amplitude as shown in Figure 5 for two low frequency intervals, in Figure 6 for two medium frequency intervals, and in Figure 7 for two high frequency intervals. The figures show that for the two high frequency intervals the separation between cluster points characteristic of the two depth of cut values is very good.

The same can be seen if the "difference signal" maximum amplitude is plotted versus depth of cut as shown in Figure 8 for low, medium and high frequency intervals.

At low frequencies $(0-0.25 \mathrm{kHz} ; 0.25-0.5 \mathrm{kHz})$, the $S$ a diff $\mathrm{MAX}$ value is around $10 \mathrm{~dB}$ for both depth of cut values $(0.5$ and $1 \mathrm{~mm})$. In this case, depth of cut discrimination is unfeasible. However, at high frequencies $(1-2.5 \mathrm{kHz} ; 2.5-5 \mathrm{kHz})$ the $S a$ diff $\mathrm{MAX}_{\mathrm{X}}$ value is around $10 \mathrm{~dB}$ for depth of cut $0.5 \mathrm{~mm}$ and around $30 \mathrm{~dB}$ for a depth of cut $1 \mathrm{~mm}$ and recognition becomes feasible.

A supervised NN data processing was utilized for pattern recognition using the 6component feature vectors made of the "difference signal" maximum amplitudes for the 6 frequency intervals. A three-layers feed-forward back-propagation $\mathrm{NN}$ was built with the following configuration: input layer with 6 nodes; hidden layer with 3 nodes determined by the cascade learning procedure (Teti \& Buonadonna, 1999); output layer with 1 node.

The 6-3-1 NN was trained and tested according to the leave-k-out procedure with $\mathrm{k}=2$ (Teti \& Buonadonna, 1999), using a number of learning steps comprised between 1000 and 14000 . In Figure 9, the NN output is reported versus the number of input patterns for 12000 and 14000 learning steps. From this figure, it can be seen that the NN Success Rate (SR) in the identification of depth of cut becomes $100 \%$ after 14000 learning steps.

Figure 10 reports the NN SR versus learning steps for different treshold values. From the figure, it can be noted that the NN SR is $85 \%$ as early as 2000 learning steps.

Figure 11 reports the NN SR versus threshold value for variable numbers of learning steps. From the figure, it can be observed that the NN SR starts decreasing gradually only for threshold values $<0.3$, except in the case of the lowest number of learning steps (i.e. 1000) for which a rapid SR reduction is expectedly verified. 


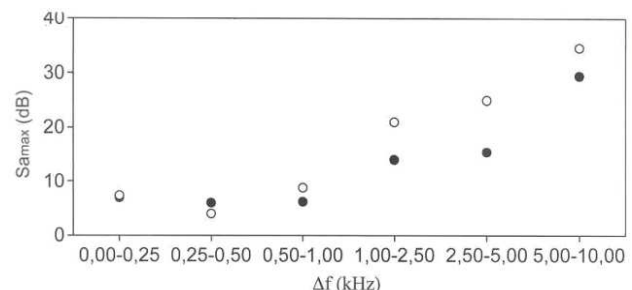

a)

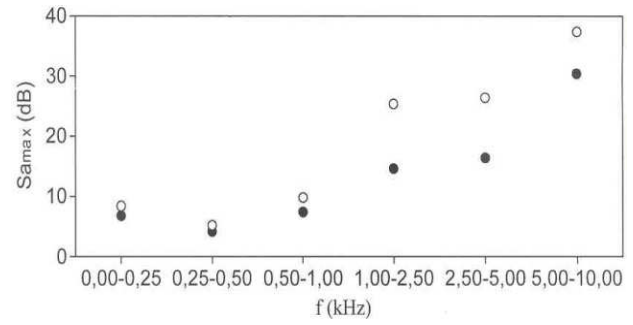

c)

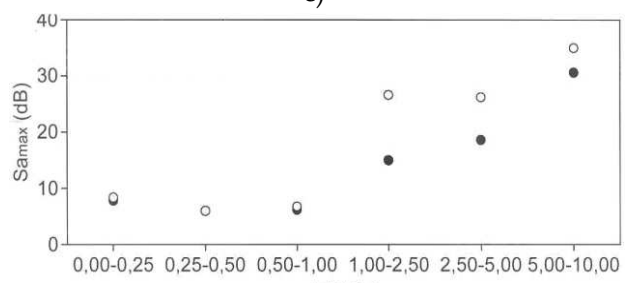

$\Delta \mathrm{f}(\mathrm{kHz})$

e)

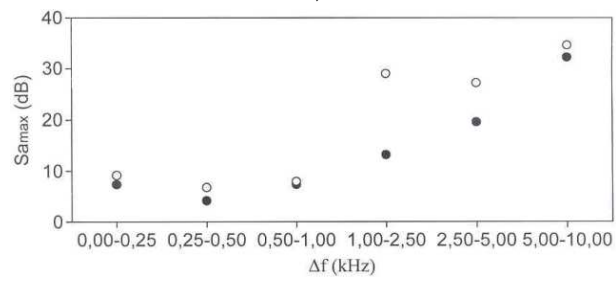

g)

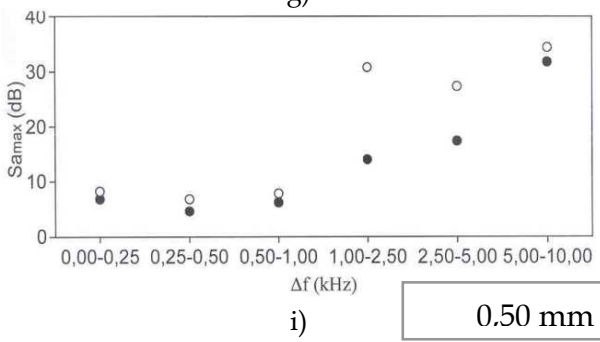

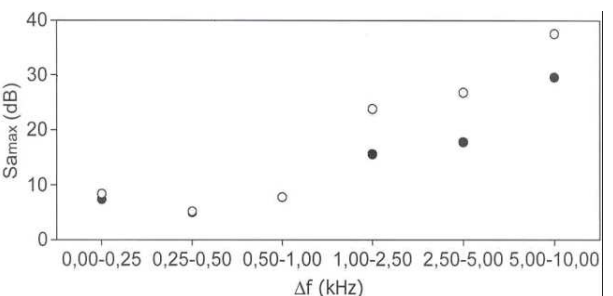

b)

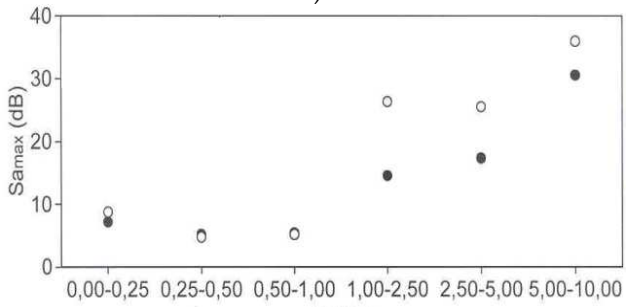

$\Delta \mathrm{f}(\mathrm{kHz})$

d)

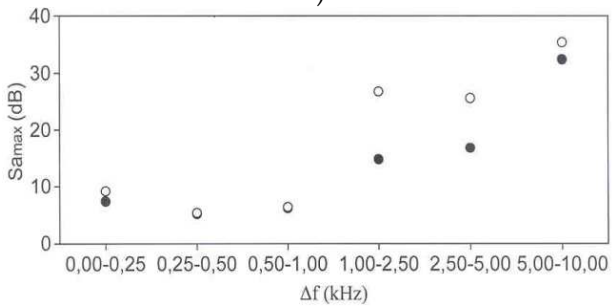

f)

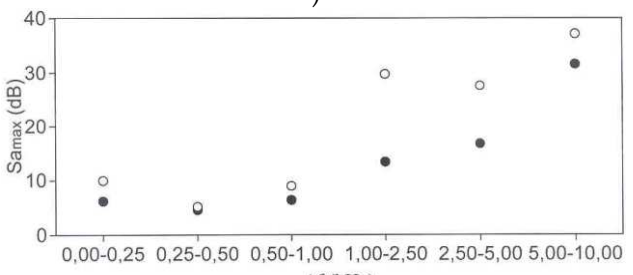

$\mathrm{h})$

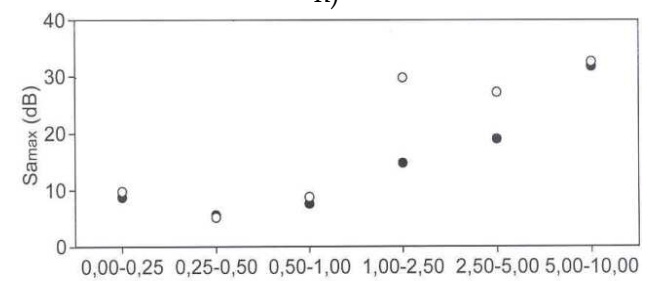

$\Delta \mathrm{f}(\mathrm{kHz})$

Fig. 4. "Difference signal" maximum amplitude $S a$ diff $f_{M A X}(\mathrm{~dB})$ vs. frequency intervals $\Delta f$ $(\mathrm{Hz})$ for the $S=800 \mathrm{rpm}, f=80 \mathrm{~mm} / \mathrm{min}$, and $d=0.5$ or $1 \mathrm{~mm}$ cases, for each of the ten seconds of cutting test: a) first; b) second; c) third; d) fourth; e) fifth; f) sixth; g) seventh; h) eighth; i) ninth; j) tenth second. 


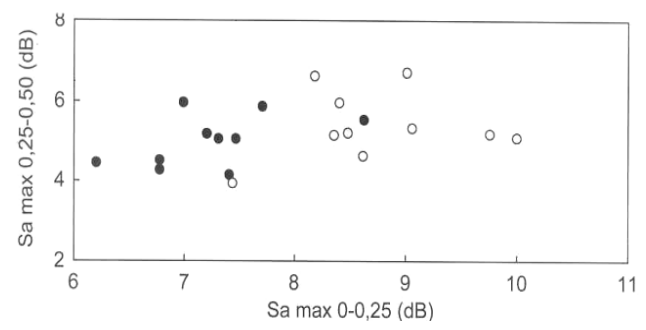

a)

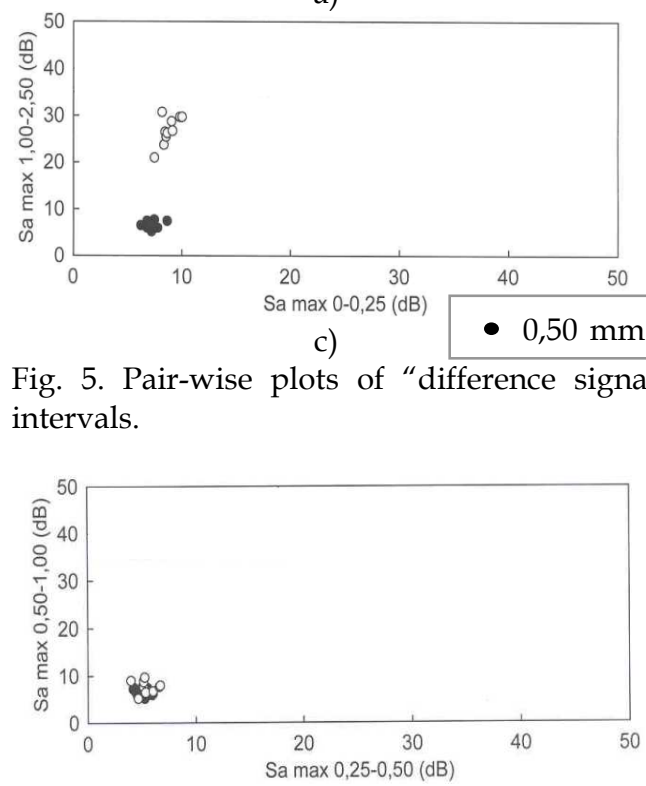

a)

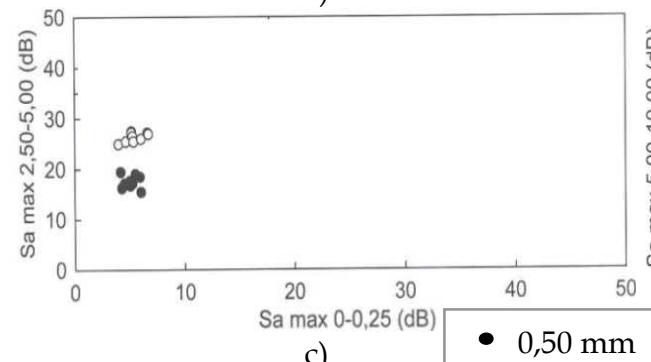

c)

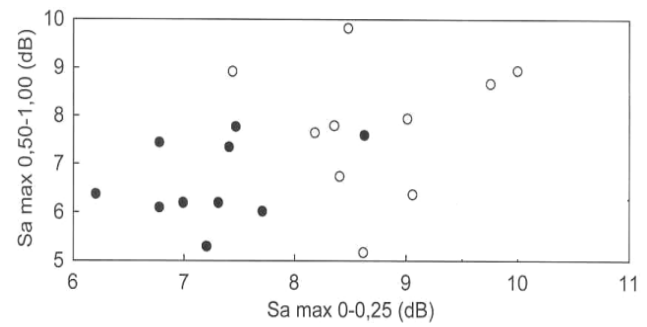

b)

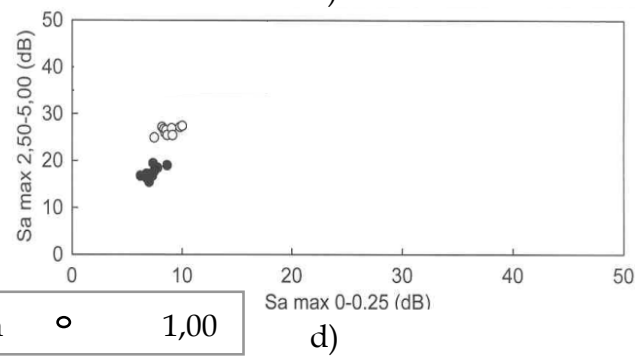

maximum amplitudes for low frequency

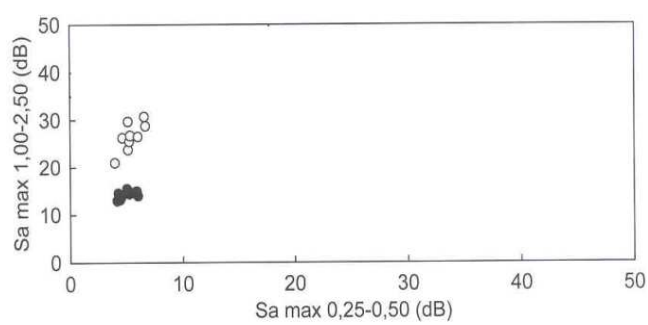

b)

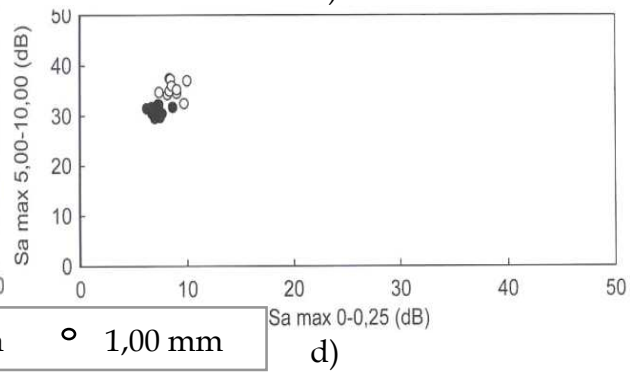

Fig. 6. Pair-wise plots of "difference signal" maximum amplitudes for medium frequency intervals. 

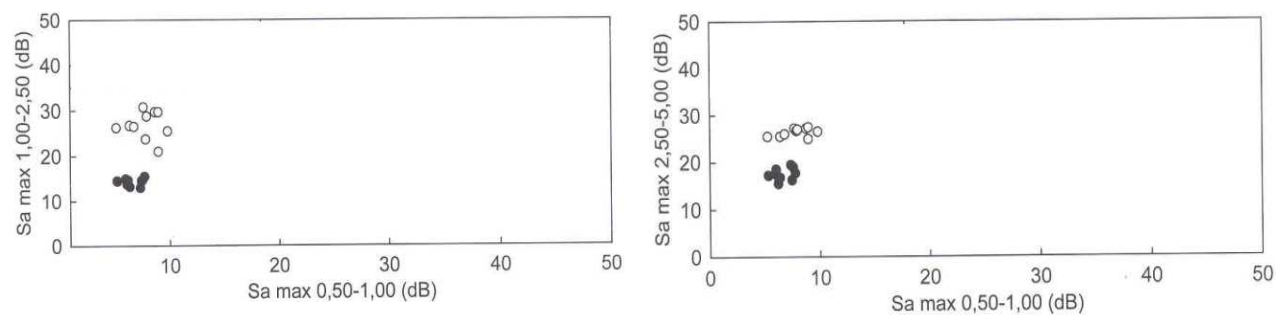

a)

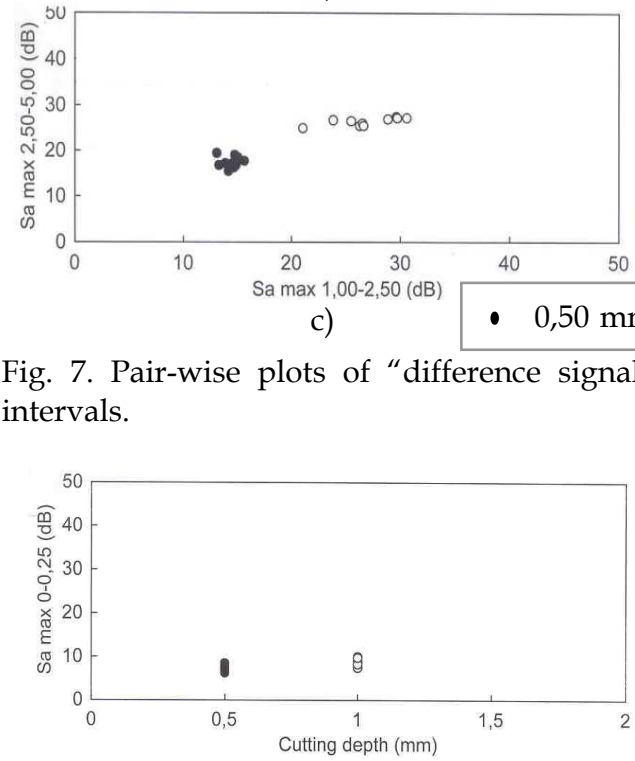

b)

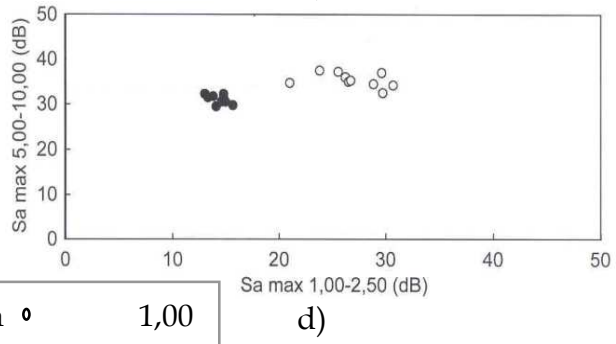

Fig. 7. Pair-wise plots of "difference signal" maximum amplitudes for high frequency intervals.

a)

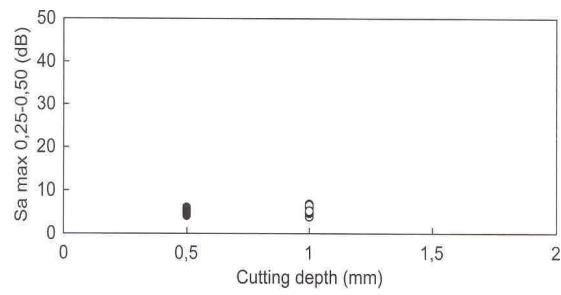

b)

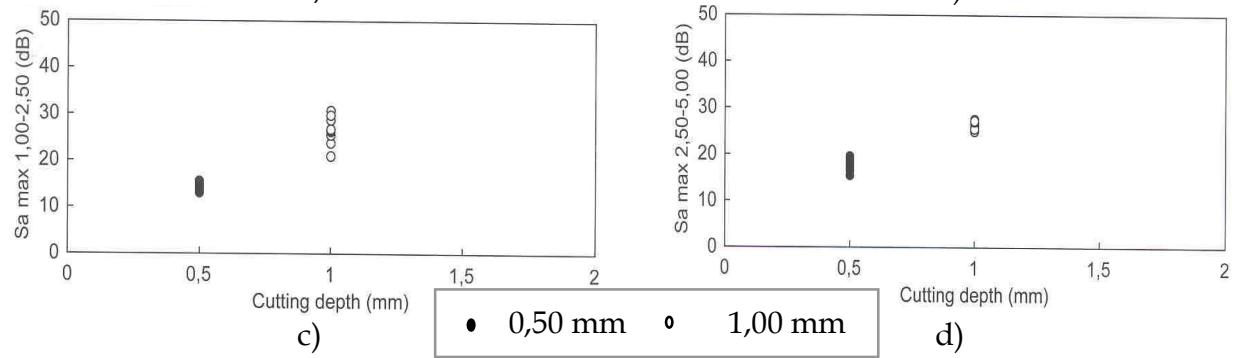

Fig. 8. "Difference signal" maximum amplitudes vs. depth of cut. 


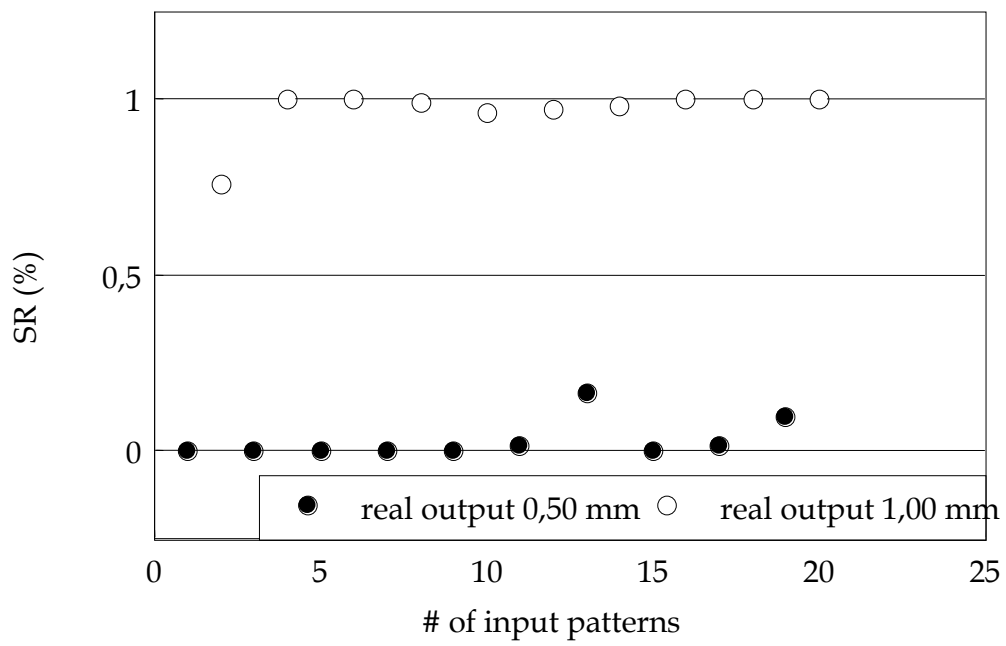

a)

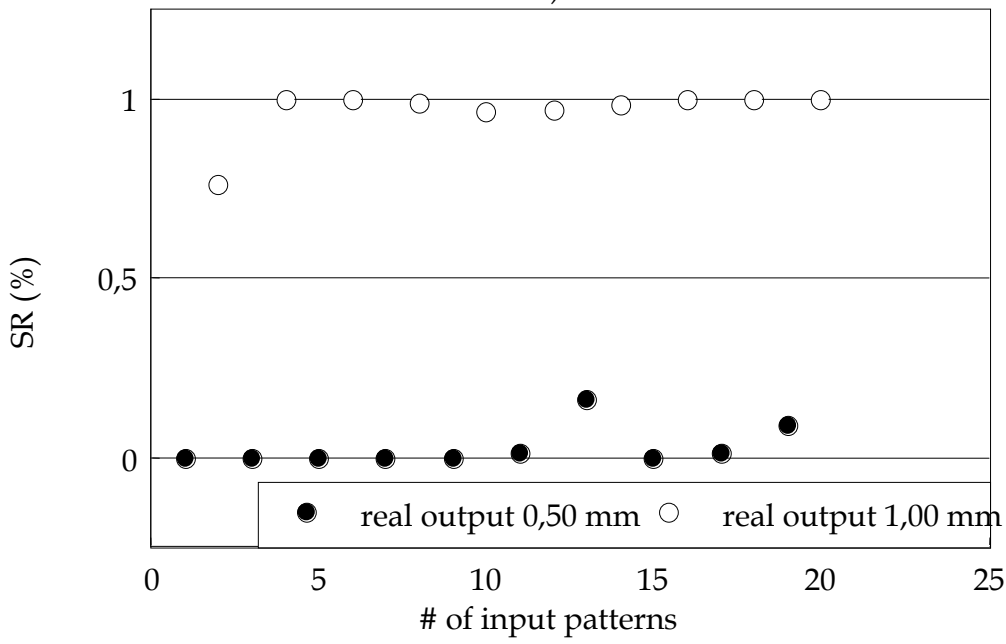

b)

Fig. 9. Neural Network output vs. number of input patterns for: a) 12000 and b) 14000 learning steps. 


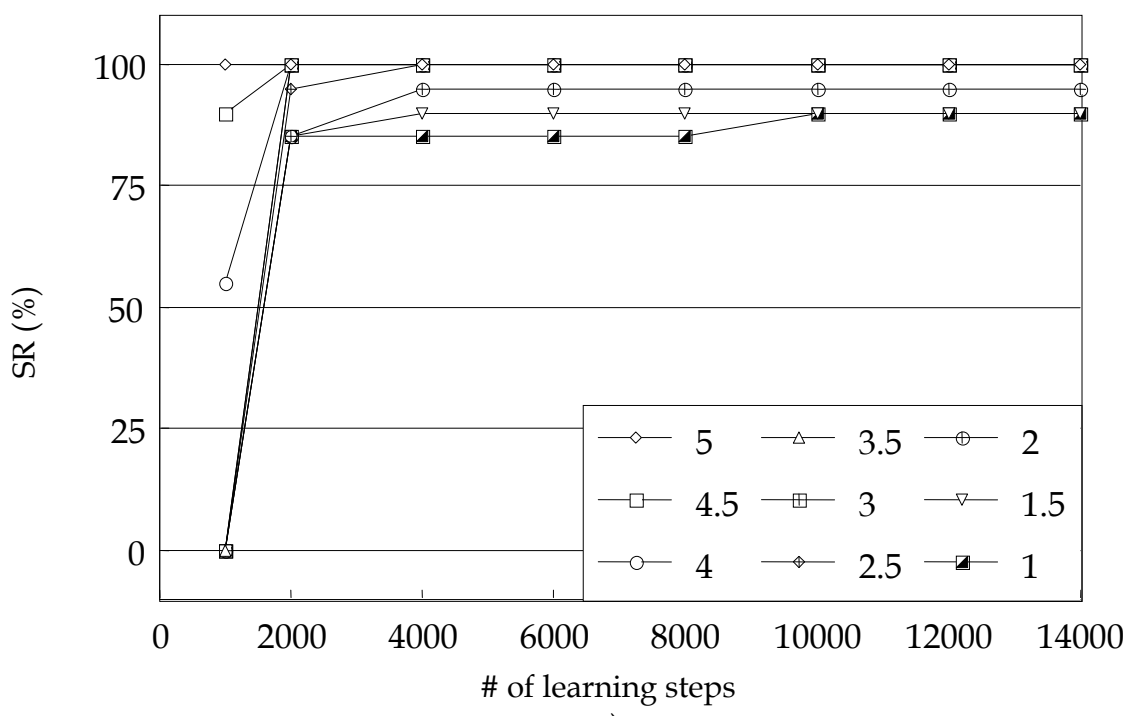

a)

Fig. 10. Neural Network Success Rate vs. number of learning steps for different threshold values.

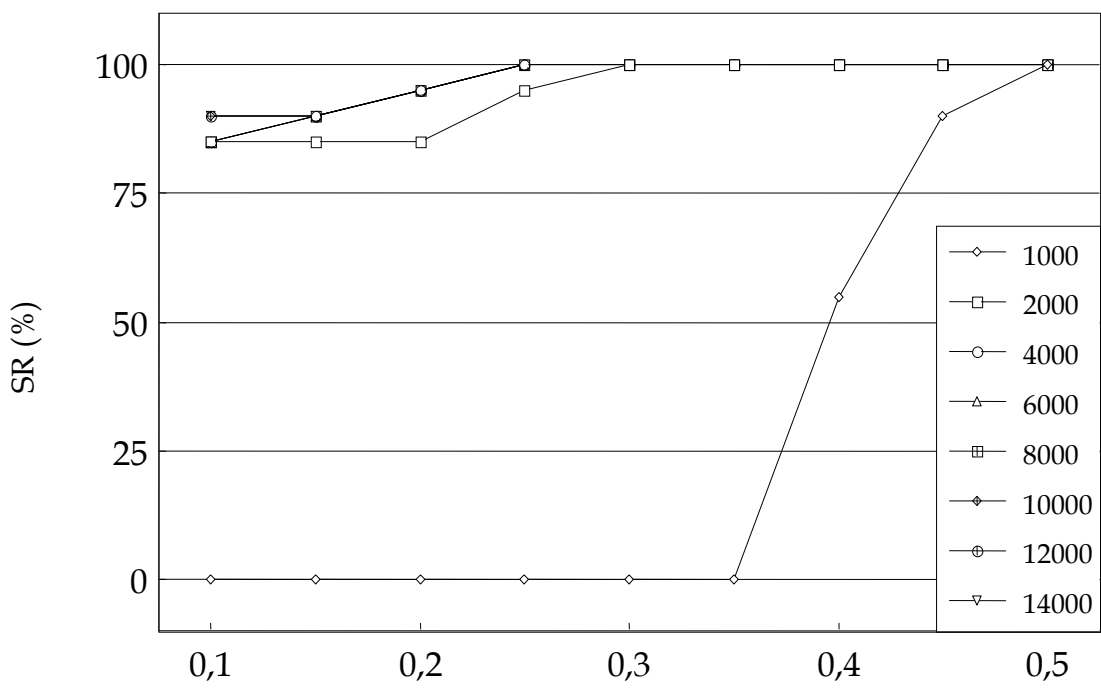

Threshold value

Fig. 11. Neural Networks Success Rate vs. threshold value for different numbers of learning steps. 


\section{Conclusion}

During the last years, notable efforts have been made to develop reliable and industrially applicable machining monitoring systems based on different types of sensors, especially in production environments that require fully unmanned operation such as Flexible Manufacturing Systems (FMS) or Computer Integrated Manufacturing (CIM).

The main focus of this work is the establishment of a methodology to implement a process monitoring system based on audible sound energy sensors for application to milling operations.

In order to characterise the audible sound energy signals emitted by different cutting conditions during milling of T4-6056 Al alloy plates, machining parameters were varied and the corresponding acoustic signals were detected and processed in the frequency domain by a real-time spectrum analyser.

The classification of audible sound signal features was performed in twodimensional space by graphical analysis and in multi-dimensional spaces by parallel distributed data processing using a supervised Neural Network paradigm. The experimental results showed that the identification of depth of cut variation can realised only with reference to high frequency ranges. Besides, the supervised Neural Network data processing proved that the recognition of depth of cut value can be reliably achieved independently of the frequency range.

The proposed approach allows to state that: (1) the application of a systematic methodology to set up the cutting tests permits a more thorough comparison with other similar experimental works; (2) sensor signal analysis independent of the noise generated by the machine tool and the working environment is obtainable by subtracting the noise characteristic signal from the signals detected during the cutting tests; (3) the results obtained in this approach can be utilized for the development of process monitoring procedures based on sensors of different types, such as acoustic emission sensors where the high frequency $(>20 \mathrm{kHz})$ stress waves produced within the work material do not travel through air but only in the material itself. The combined application of audible sound energy sensors and acoustic emission sensors could make available more comprehensive information on process conditions through both low frequency (audible sound) and high frequency (acoustic emission) signal analysis, realizing the concept of sensor fusion technology.

\section{Acknowledgements}

Funding for this work was partly provided by the Spanish Ministry of Education and Science (Directorate General of Research), Project DPI2008-06771-C04-02.

The activity for the preparation of this work has received funding support from the European Community's Seventh Framework Programme FP7/2007-2011 under grant agreement no. 213855 . 


\section{References}

Brophy, C., Kelly, K., Byrne, G. (2002) AE-based condition monitoring of the drilling process. Journal of Materials Processing Technology, 124, 3, 305-310, ISSN: 0924-0136.

Burke, L.I., Rangwala, S. (1991) Tool condition monitoring in metal cutting. A neural network approach. Journal of Intelligent Manufacturing, 2, 5, 269-280, ISSN: 09565515.

Byrne, G., Dornfeld, D., Inasaki, I., Ketteler, G., König, W., Teti, R. (1995) Tool Condition Monitoring (TCM) - The Status of Research and Industrial Application. Annals of the CIRP, 44, 2, 541-567, ISSN: 0007-8506.

CA-Cricket Graph III For Macintosh: Version 1.0, User Guide, 1992.

Chen, C., Lee, S., Santamarina, G. (1994) An object-oriented manufacturing control system. Journal of Intelligent Manufacturing, 5, 5, 315-321, ISSN: 0956-5515.

Chen, F.F., Huang, J., Centeno, M.A. (1999) Intelligent scheduling and control of rail-guided vehicles and load/unload operations in a flexible manufacturing system. Journal of Intelligent Manufacturing, 10,5, 405-421, ISSN: 0956-5515.

Chen, J.C. (2000) An effective fuzzy-nets training scheme for monitoring tool breakage. Journal of Intelligent Manufacturing, 11,1, 85-101, ISSN: 0956-5515.

Chen, J.C., Chen, W.L. (1999) A tool breakage detection system using an accelerometer sensor. Journal of Intelligent Manufacturing, 10, 2, 187-197, ISSN: 0956-5515.

Cho, D.W., Lee, S.J., Chu, C.N. (1999) The state of machining process monitoring research in Korea. International Journal of Machine Tools and Manufacturing, 39, 11, 1697-1715, ISSN: 0890-6955.

Clark, W.I., Shih, A.J., Hardin, C.W., Lemaster, R.L., McSpadden, S.B. (2003) Fixed abrasive diamond wire machining-part I: process monitoring and wire tension force. International Journal of Machine Tools Manufacturing, 43, 5, 523-532, ISSN: 0890-6955.

D'Errico, G.E. (1997) Adaptive systems for machining process monitoring and control. Journal of Materials Processing Technology, 64, 1-3, 75-84, ISSN: 0924-0136.

Desforges, X., Habbadi, A., Geneste, L., Soler, F. (2004) Distributed machining control and monitoring using smart sensors/actuators. Journal of Intelligent Manufacturing, 15, 1, 39-53, ISSN: 0956-5515.

Dornfeld, D.A. (1992) Monitoring of machining process - Literature Review. Annals of the CIRP, 41, 1, 93-96, ISSN: 0007-8506.

Emel, E. (1991) Tool wear detection by neural network based acoustic emission sensing. ASME, Dynamic Systems and Control Division Publication, 28, 79-85, ISSN: 0022-0434.

Fu, J.C., Troy, C.A., Mori, K. (1996) Chatter classification by entropy functions and morphological processing in cylindrical traverse grinding. Precision Engineering,18, 2-3, 110-117, ISSN: 0141-6359.

Govekar, E., Gradišek, J., Grabec, I. (2000) Analysis of acoustic emission signals and monitoring of machining processes. Ultrasonics, 38, 1-8, 598-603, ISSN: 0041-624X.

Grabec, I., Govekar, E., Susic, E., Antolovic, B. (1998) Monitoring manufacturing processes by utilizing empirical modelling. Ultrasonics, 36, 1-5, 263-271, ISSN: 0041-624X.

Hong, S.Y. (1993) Knowledge-based diagnosis of drill conditions. Journal of Intelligent Manufacturing, 4, 3, 233-241, ISSN: 0956-5515.

Hou, T.H., Liu, W.L., Lin, L. (2003) Intelligent remote monitoring and diagnosis of manufacturing processes using an integrated approach of neural networks and rough sets. Journal of Intelligent Manufacturing, 14, 2, 239-253, ISSN: 0956-5515. 
Huang, P.T., Chen, J.C. (1998) Fuzzy logic-base tool breakage detecting system in end milling operations. Computers and Industrial Engineering, 35, 1-2, 37-40, ISSN: 03608352.

Inasaki, I., (1998) Application of acoustic emission sensor for monitoring machining processes. Ultrasonics, 36, 1-5, 273-281, ISSN: 0041-624X.

Jemielniak, K., Kwiatkowski, L., Wrzosek, P. (1998) Diagnosis of tool wear based on cutting forces and acoustic emission measures as inputs to a neural network. Journal of Intelligent Manufacturing, 9, 5, 447-455, ISSN: 0956-5515.

Jin, J., Shi, J. (2001) Automatic feature extraction of waveform signals for in-process diagnostic performance improvement. Journal of Intelligent Manufacturing, 12, 3, 257268, ISSN: 0956-5515.

Karlsson, B., Karlsson, N., Wide, P. (2000) A dynamic safety system based on sensor fusion. Journal of Intelligent Manufacturing, 11, 5, 475-483, ISSN: 0956-5515.

Kopac, J., Sali, S. (2001) Tool wear monitoring during the turning process. Journal of Materials Processing Technology, 113, 312-316, ISSN: 0924-0136.

Larson Davis Laboratory, 2800 Manual, Preliminary Documentation 1/27/93.

Lin, B., Zhu, M.Z., Yu, S.Y., Zhu, H.T., Lin, M.X. (2002) Study of synthesis identification in the cutting process with a fuzzy neural network. Journal of Materials Processing Technology, 129, 1-3, 131-134, ISSN: 0924-0136.

Lu, M.C., Kannatey-Asibu, E. Jr. (2000) Analysis of sound signal generation due to flank wear in turning. International ME2000 Congress \& Exposition, Orlando, FL.

Malakooti, B.B., Zhou, Y.Q., Tandler, E.C. (1995) In-process regressions and adaptive multicriteria neural networks for monitoring and supervising machining operations. Journal of Intelligent Manufacturing, 6, 1, 53-66, ISSN: 0956-5515.

Masory, O. (1991) Monitoring machining processes using multi-sensor readings fused by artificial neural network. Journal of Materials Processing Technology, 28, 1-2, 231-240, ISSN: 0924-0136.

Masters, T. (1993) Practical Neural Networks Recipies in C++, Academic Press, San Diego, CA.

Niu, Y., Wong, Y., Hong, G. (1998) Intelligent sensor system approach for reliable tool flank wear recognition. International Journal of Advanced Manufacturing Technology, 14, 2, 77-84, ISSN: 0268-3768.

Noise and Vibrations Works, References Manual version 1.22.

Okafor, C., Adetona, O. (1995) Predicting quality characteristics of end-milled parts based on multi-sensor integration using neural networks, individual effects of learning parameters and rules. Journal of Intelligent Manufacturing, 6, 6, 389-400, ISSN: 09565515.

Ouafi, A.E., Guillot, M., Bedrouni, A. (2000) Accuracy enhancement of multi-axis CNC machines through on-line neurocompensation. Journal of Intelligent Manufacturing, 11, 6, 535-545, ISSN: 0956-5515.

Peng, Y. (2004) Intelligent condition monitoring using fuzzy inductive learning. Journal of Intelligent Manufacturing, 15, 3, 373-380, ISSN: 0956-5515.

Rubio, E.M., Teti, R. (2004) Cutting tests definition for effective tool condition monitoring. IFAC-MIM '04, Int. Conf. on Manufacturing, Modelling, Management and Control, Athens, 21-22 Oct. 
Rubio, E.M., Teti, R., Baciu, I.L. (2006) Advanced signal processing in acoustic emission monitoring systems for machining technology. 2nd Int. Virtual Conf. on Intelligent Production Machines and Systems - IPROMS 2006, 3-14 July: 189-192.

Rubio, E.M., Teti, R., Baciu, I.L. (2006) Main decision making procedures used in the monitoring systems of machining processes based on acoustic emission sensors. 5 th CIRP Int. Sem. on Intelligent Computation in Manufacturing Engineering CIRP ICME ‘06, Ischia, 25-28 July: 189-192.

Shawaky, A., Rosenberger, T., Elbestawi, M. (1998) In process monitoring and control of thickness error in machining hollows shafts. Mechatronics, 8, 301-322.

Sokolowski, A., Kosmol, J. (2001) Selected examples of cutting process monitoring and diagnostics. Journal of Materials Processing Technology, 113, 1-3, 322-330, ISSN: 09240136.

Spectrum Pressure Lavel (Spl 3100), Manual Version 0.98, Program Version 1.10.

Teti, R., Buonadonna, P. (1999) Round Robin on Acoustic Emission Monitoring of Machining. Annals of the CIRP, 48, 3, 47-69, ISSN: 0007-8506.

Teti, R., (1995) A Review of Tool Condition Monitoring a Literature. Annals of the CIRP, 44, 2, 659-666, ISSN: 0007-8506.

Teti, R., Baciu, I.L. (2004) Neural network processing of audible sound signal parameters for sensor monitoring of tool conditions. 4th CIRP Int. Sem. on Intelligent Computation in Manufacturing Engineering - CIRP ICME '04, Sorrento, 30 June - 2 July: 385-390.

Teti, R., Baciu, I.L., Rubio, E.M. (2004) Neural network classification of audible sound signals for process monitoring during machining. Annals of DAAAM for 2004 \& Proc. 15th Int. DAAAM Symp. on Intelligent Manufacturing Systems: Globalisation-Technology-Man-Nature, Ed. B. Katalinic, DAAAM International, ISSN 1726-9679, ISBN 3-901509-42-9: 459-460.

Tönshoff, H.K., Wulsferg, J.P., Kals, H.J., Köning, W., Van Luttervelt, C.A. (1988) Developments and Trends in Monitoring and Control of Machining Processes. Annals of the CIRP, 37, 2, 611-622, ISSN: 0007-8506.

Venkatesh, K., Zhou, M., Caudill, R.J. (1997) Design of artificial neural networks for tool wear monitoring. Journal of Intelligent Manufacturing, 8, 3, 215-226, ISSN: 0956-5515.

Wilcos, S.J., Reuben, R.L., Souquet, P. (1997) The use of cutting force and acoustic emission signals for the monitoring the tool insert geometry during rough face milling. International Journal of Machine Tools Manufacturing, 32, 4, 481-494, ISSN: 0890-6955.

Xiaoli, L., Yingxue, Y., Zhejun, Y. (1997) On-line tool condition monitoring system with wavelet fuzzy neural network. Journal of Intelligent Manufacturing, 8, 4, 271-276, ISSN: 0956-5515.

$\mathrm{Xu}, \mathrm{Y} ., \mathrm{Ge}, \mathrm{M}$. (2004) Hidden Markov model-based process monitoring system. Journal of Intelligent Manufacturing, 15, 3, 337-350, ISSN: 0956-5515. 


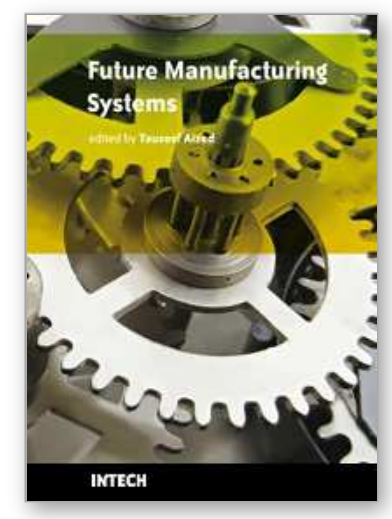

\author{
Future Manufacturing Systems \\ Edited by Tauseef Aized
}

ISBN 978-953-307-128-2

Hard cover, 268 pages

Publisher Sciyo

Published online 17, August, 2010

Published in print edition August, 2010

This book is a collection of articles aimed at finding new ways of manufacturing systems developments. The articles included in this volume comprise of current and new directions of manufacturing systems which I believe can lead to the development of more comprehensive and efficient future manufacturing systems. People from diverse background like academia, industry, research and others can take advantage of this volume and can shape future directions of manufacturing systems.

\title{
How to reference
}

In order to correctly reference this scholarly work, feel free to copy and paste the following:

Eva Rubio (2010). Machining Process Monitoring System Using Audible Energy Sound Sensors, Future Manufacturing Systems, Tauseef Aized (Ed.), ISBN: 978-953-307-128-2, InTech, Available from: http://www.intechopen.com/books/future-manufacturing-systems/machining-process-monitoring-system-usingaudible-energy-sound-sensors

\section{INTECH}

open science | open minds

\author{
InTech Europe \\ University Campus STeP Ri \\ Slavka Krautzeka 83/A \\ 51000 Rijeka, Croatia \\ Phone: +385 (51) 770447 \\ Fax: +385 (51) 686166 \\ www.intechopen.com
}

\author{
InTech China \\ Unit 405, Office Block, Hotel Equatorial Shanghai \\ No.65, Yan An Road (West), Shanghai, 200040, China \\ 中国上海市延安西路65号上海国际贵都大饭店办公楼405单元 \\ Phone: +86-21-62489820 \\ Fax: $+86-21-62489821$
}


(C) 2010 The Author(s). Licensee IntechOpen. This chapter is distributed under the terms of the Creative Commons Attribution-NonCommercialShareAlike-3.0 License, which permits use, distribution and reproduction for non-commercial purposes, provided the original is properly cited and derivative works building on this content are distributed under the same license. 